Article

\title{
Design and Mechanical Properties Analysis of AA5083 Ultrafine Grained Cams
}

\author{
Daniel Salcedo, Carmelo J. Luis *, Rodrigo Luri, Ignacio Puertas, Javier León and Juan P. Fuertes \\ Mechanical, Energetics and Materials Engineering Department, Public University of Navarre, \\ Campus Arrosadía s/n, 31006 Pamplona, Navarra, Spain; daniel.salcedo@unavarra.es (D.S.); \\ rodrigo.luri@unavarra.es (R.L.); inaki.puerta@unavarra.es (I.P.); javier.leon@unavarra.es (J.L.); \\ juanpablo.fuertes@unavarra.es (J.P.F.) \\ * Correspondence: cluis.perez@unavarra.es; Tel.: +34-948-169-301
}

Academic Editor: Myoung-Gyu Lee

Received: 14 February 2017; Accepted: 22 March 2017; Published: 28 March 2017

\begin{abstract}
This present research work deals with the development of ultrafine grained cams obtained from previously ECAP (Equal Channel Angular Pressing)-processed material and manufactured by isothermal forging. The design and the manufacturing of the dies required for the isothermal forging of the cams are shown. Optimization techniques based on the combination of design of experiments, finite element and finite volume simulations are employed to develop the dies. A comparison is made between the mechanical properties obtained with the cams manufactured from material with no previous deformation and with those from previously SPD (Severe Plastic Deformation)-processed material. In addition, a comparative study between the experimental results and those obtained from the simulations is carried out. It has been demonstrated that it is possible to obtain ultrafine grained cams with an increase of $10.3 \%$ in the microhardness mean value as compared to that obtained from material with no previous deformation.
\end{abstract}

Keywords: isothermal forging; design; FEM; ECAP; DOE

\section{Introduction}

One of the most interesting aspects of dealing with cam design is the material employed in its manufacturing as this is directly related to the tribological behaviour of the mechanical component [1]. Inertia loads may cause some undesirable behaviour in the case of mechanical devices of type cam-follower, as is stated in Lee and Lee [2], and one of the most practical solutions is to reduce mass. This solution is in line with the use of nanostructured materials in order to manufacture the cam, where this leads to higher values of mechanical strength at lower weight values.

As is well-known, the most widespread Severe Plastic Deformation (SPD) process is Equal Channel Angular Pressing (ECAP). This process, which was initially proposed by V.M. Segal and his co-workers in the former Soviet Union [3], consists in compressing a material through a die with two channels with practically the same cross-section and at an angle which varies from $90^{\circ}$ to $120^{\circ}$ [4]. There have been a large number of research papers which deal with the ECAP process of different metallic materials, especially aluminium alloys [5-11].

Nevertheless, the number of practical applications to the manufacturing of mechanical components is still scant. Some of the most remarkable mechanical components manufactured from SPD materials in the existing bibliography are mentioned below.

In relation to the manufacturing of gears from ECAP-processed materials, research work from both Kim et al. [12] and Luis Pérez et al. [13] are noteworthy. From ECAP-processed AA6061 (twelve times using route $\mathrm{Bc}$ ), Kim et al. [12] manufacture a micro-gear by extrusion at temperature values of $443 \mathrm{~K}$ and $553 \mathrm{~K}$. One of their most remarkable conclusions is that the extrusion process may be carried 
out with no significant loss of the mechanical properties now improved by the previous ECAP process. Luis Pérez et al. [13] manufacture two different gears from ECAP-processed AA5083 by isothermal forging: one with a module of 2 and another with a module of 4 . In the case of the 4 module gear, after having been forged from ECAP-processed AA5083, its microhardness value is between $8.6 \%$ and $13.6 \%$ higher than that from the gear forged with annealed AA5083.

As far as is known, most of the practical applications of mechanical components deal with the manufacturing of bolts. Choi et al. [14] propose the manufacturing of high strength bolts from ECAP-processed AA1050, where, in order to obtain this ultra-fine grained material, AA1050 is subjected to the ECAP process at room temperature up to three passages with routes $\mathrm{A}, \mathrm{Bc}$ and $\mathrm{C}$. Three stages are used in the bolt forming process as well as a final thread-machining stage. In this way, these authors achieve an ultimate tensile strength for the ultra-fine grained bolts which is two times higher than that of the conventional ones. In the research work from Yanagida et al. [15], the formability of four different ECAP-processed carbon steel materials is studied. This is carried out by means of the manufacturing of M1.6 micro-bolts. One of the most important conclusions is that the formability of the ECAP-processed carbon steel undergoes a low reduction compared to the non-processed material.

There have been several attempts made to improve the industrial applicability of the ECAP process (above all, in terms of continuity) in the manufacturing of bolts. For instance, in research work from Jin et al. [16] and Jin et al. [17], a spring-loaded ECAP system is proposed. In this newly proposed system, a wire rod is cut into the starting billet and this is automatically transferred to the ECAP die, where there is a sliding tool to form the die channels. A commercial multi-stage former is also installed to manufacture the bolts in four stages: extrusion, upsetting, pre-heading and finish heading. As shown in Jin et al. [17], the bolts are manufactured from ECAP-processed AA6061 and their resulting ultimate tensile strength is $7.9 \%$ higher than those conventionally manufactured.

Another attempt to develop a continuous process in order to manufacture bolts is carried out by Kim et al. [18]. These authors use a two-pass hybrid process, which consists of a series of pinch rolls, an ECAP die and a wire-drawing die. AA6061 wire is passed twice through the hybrid process in a continuous manner with routes $\mathrm{A}$ and $\mathrm{C}$. Then, a forming process, which is composed of three stages, is used to manufacture M4.5 bolts from this ECAP-processed wire. Four cases are studied and compared: two-pass hybrid process with route $\mathrm{A}$ (Case 1), two-pass hybrid process with route $\mathrm{C}$ (Case 2), two-pass wire-drawing (Case 3) and three-pass wire-drawing (Case 4). It is found that the two-pass hybrid process with route $C$ turns out to be the most uniform and it achieves the highest mechanical property values in terms of microhardness and ultimate tensile strength.

Other examples of mechanical components that have been manufactured from ECAP-processed materials are blades and impellers. Puertas et al. [19] study the manufacturing of Francis turbine blades from ECAP-processed AA1050. Once ECAP-processed AA1050 is obtained, blades are manufactured by isothermal forging at temperature values from 25 to $200{ }^{\circ} \mathrm{C}$. A considerable increase in the microhardness of the previously ECAP-processed blades is achieved compared to that obtained from the annealed material, where this is approximately of some $25 \%$ for all the temperature range considered. Lee et al. [20] develop a forging process in order to manufacture an impeller with twisted blades of micro-thickness (from 400 to $600 \mu \mathrm{m}$ ). The impeller is forged from an AZ31 magnesium alloy which is previously ECAP-processed with four initial passages at $400{ }^{\circ} \mathrm{C}$ followed by five additional passages at $250{ }^{\circ} \mathrm{C}$ with route $\mathrm{Bc}$. The forging process is carried out at a temperature value of $300{ }^{\circ} \mathrm{C}$ and at a strain rate value of $0.001 \mathrm{~s}^{-1}$. Under these conditions, a complete forging die filling is achieved.

Another noteworthy application by Luis et al. [21] is the manufacturing of nanostructured rings from ECAP-processed AA5083. The AA5083 billets are previously ECAP-processed twice with route $\mathrm{C}$ and then they are subjected to two stages of isothermal forging after a specific heat treatment. The optimum forging temperature is at $250{ }^{\circ} \mathrm{C}$ as, at $200{ }^{\circ} \mathrm{C}$, cracks appear in the forged rings. The specific heat treatment consists of an increase in temperature from room temperature to $340{ }^{\circ} \mathrm{C}$ at a heating rate of $12^{\circ} \mathrm{C} / \mathrm{min}$. 
Cisar et al. [22] manufacture a knuckle arm, which forms part of the steering system of an automobile, from ECAP-processed AZ31 magnesium alloy. AZ31 is subjected to up to four ECAP passages at a temperature of $250^{\circ} \mathrm{C}$ and then, it is forged at a temperature of $150{ }^{\circ} \mathrm{C}$. One of the aims of this research work is to evaluate the applicability of ECAP-processed materials to the manufacturing of industrial components. To this end, a comparison is made between the forging of ECAP-processed AZ31, non-ECAP-processed AZ31 and AA6061 subjected to a subsequent aging treatment at $175^{\circ} \mathrm{C}$ during $8 \mathrm{~h}$.

Fuertes et al. [23] study the mechanical properties of isothermally forged connecting rods which are manufactured from previously ECAP-processed AA1050 and AA5083. This research work encompasses the design stage by finite element simulations, the experimental tests and the use of metallographic techniques for the required properties to be analysed. It is observed that there is an improvement in the mechanical properties when the starting material is ECAP-processed before carrying out the isothermal forging.

In this present research work, the manufacturing of an ultrafine grained cam is dealt with, where the initial material used is ECAP-processed AA5083 which is subsequently isothermally forged. The design of the forging dies is also carried out, with the help of techniques such as finite element (FEM) and finite volume (FV) simulations, as well as design of experiments (DOE). It is shown that the ECAP-processed cams have better mechanical properties than those obtained from non-ECAP-processed AA5083.

The aim of this present study is to compare the mechanical properties of the cams manufactured from two different starting materials; one of these following conventional manufacturing processes by isothermal forging and the other from previously ECAP-processed material.

\section{Optimization of the Die Design for Manufacturing the Cams}

In this present section, the process of design and optimization for the dies to be used in the manufacturing of the cams is outlined. Taking into consideration the dimensions of the initial material, which are limited by the ECAP press used, a cam with a difference of $10 \mathrm{~mm}$ between the maximum and the minimum radius is designed. These radii refer to the distance between the cam profile and the centre of the rotation axis. In addition to this, another design restriction is that the geometry of the cavity allows different cam profile geometries such as cycloid, harmonic and sinusoidal ones (see Figure 1), among others, to be machined. Due to the fact that it is likely that buckling and cracks will occur, the design is carried out in two forging stages: preform and final cam.
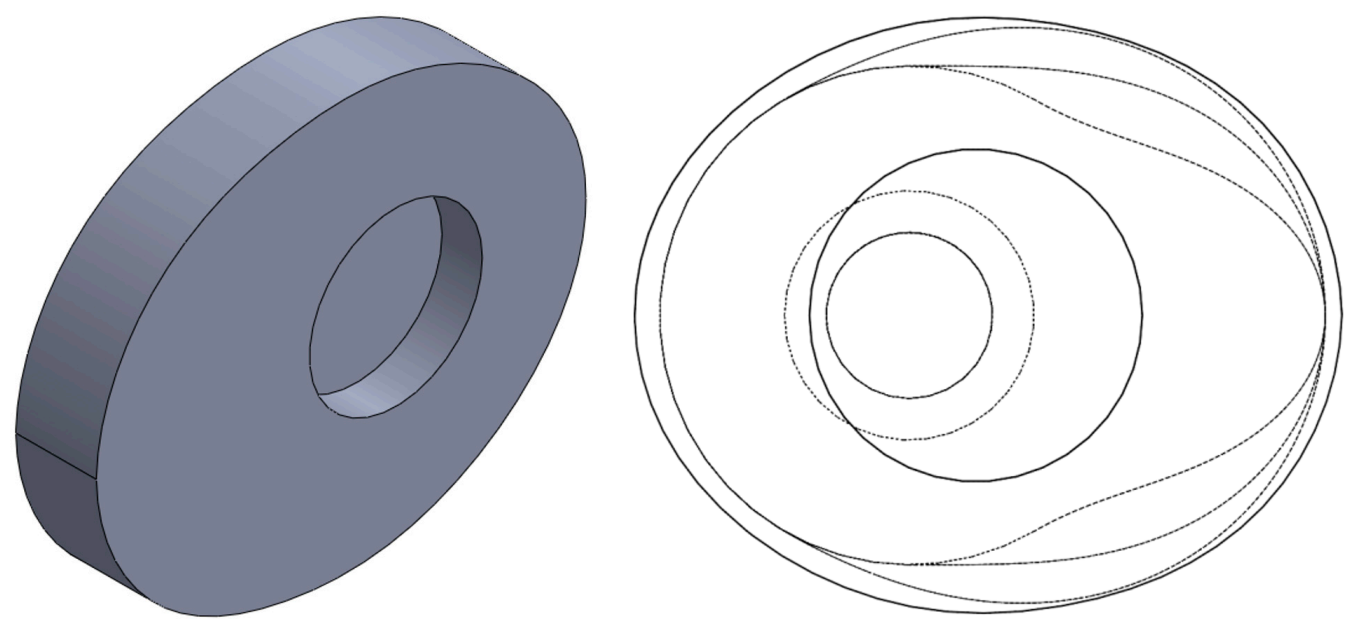

Figure 1. Basic geometry and the three types of profile. 
The design process may be observed in Figure 2. Two sets of design of experiments are planned in order to optimize the geometry of both the preform and the final cam by performing FV simulations with the software Simufact. forming $12^{\mathrm{TM}}$ (MSC Software Company, Hamburg, Germany). Subsequently, different experimental tests and FEM simulations are carried out in order to optimize the final geometry for the manufactured cam that will be shown below.

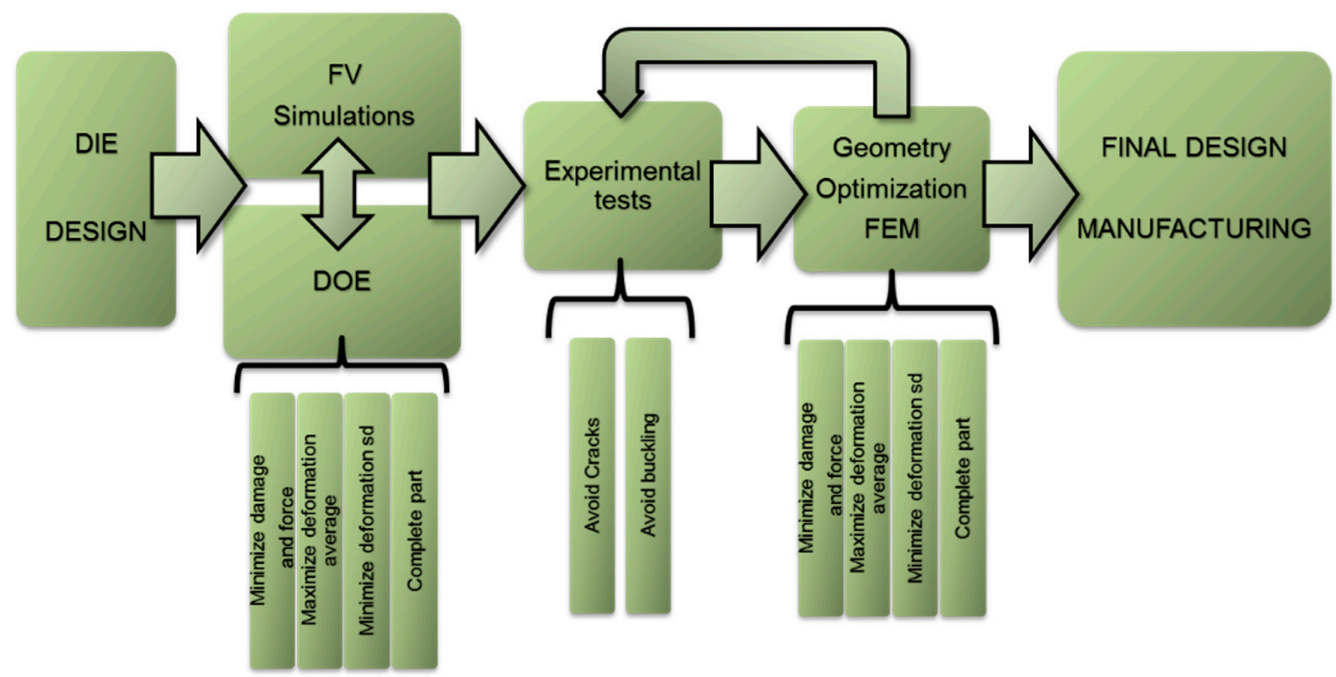

Figure 2. Optimization process for the cam design.

As previously-mentioned, the forging process is carried out in two stages. In the first of the two stages, a preform is obtained that will be subsequently forged in order to obtain the final geometry.

\subsection{Cam Preform (DOE)}

The simulations carried out in order to get the design employ a flow rule obtained from the isothermal compression of AA5083 at N2 state and at room temperature (Figure 3), as this is the most demanding case in terms of forging force and it is not possible to surpass a force value of $3000 \mathrm{kN}$, which is the maximum value the equipment allows. This flow rule is obtained from a series of compression tests over cylindrical billets of this material while temperature is kept constant, as is shown in Salcedo et al. [24].

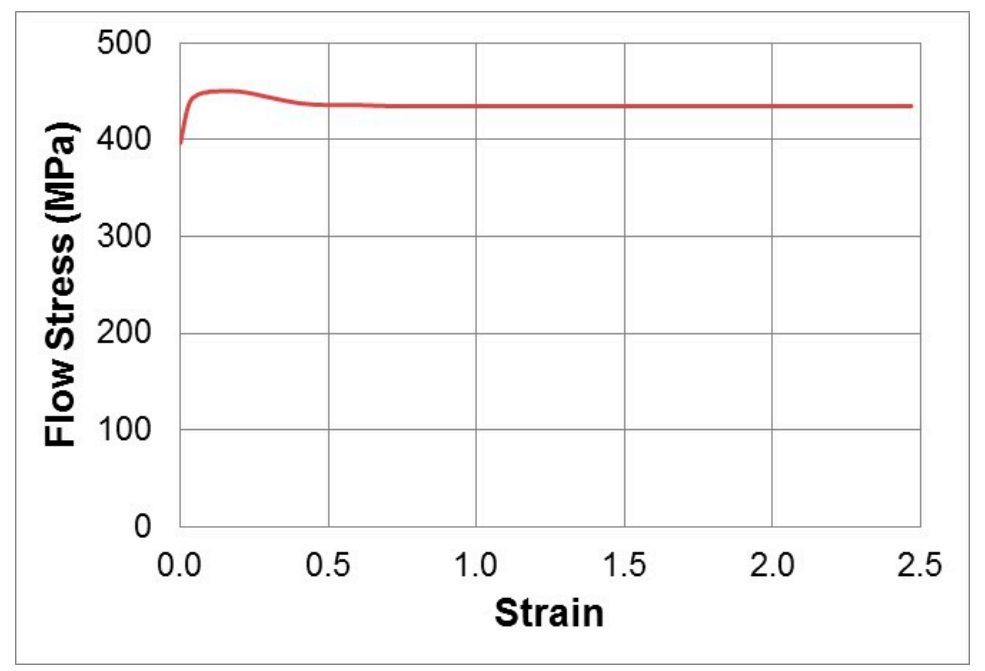

Figure 3. Flow rule fitted for AA5083 at N2 [24]. 
In order to perform the simulations, a cylindrical billet is taken with a starting diameter of $18 \mathrm{~mm}$ and an initial length of $55 \mathrm{~mm}$. Rigid dies and a meshing size for the finite volume of $1 \mathrm{~mm}$ are employed, as is shown in Figure 4. All the simulations performed have the same characteristics so that their results are not affected. Conversion of deformation energy into heat is also taken into consideration and a friction coefficient (Shear's model) of 0.3 is considered. The element employed is a triangle with three nodes at the vertices as the outer surface of the part is meshed. The minimum size of element is $0.25 \mathrm{~mm}$, whereas the cube size which models the finite volume is $1 \mathrm{~mm}$. In addition, re-meshing in the simulations is carried out every $10 \%$ of the total stroke of the upper die.

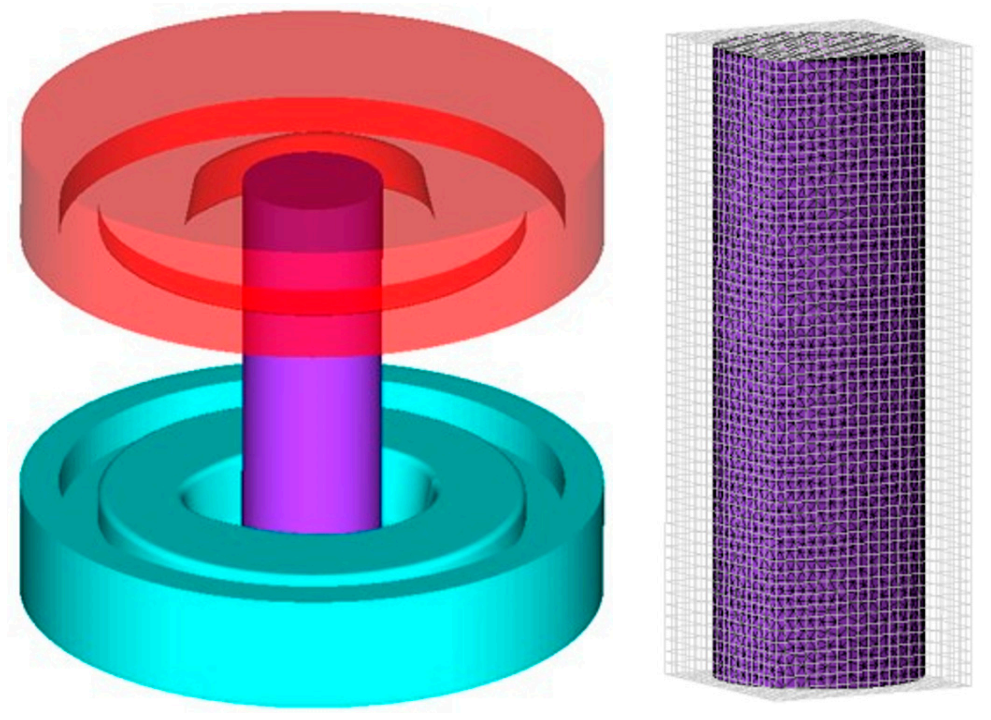

Figure 4. Simulation images from DOE Case 1.

A total of nine finite volume simulations are performed for the factorial design of experiments $2^{3}$ with the following design factors: draft angle for all the vertical surfaces, flash thickness and fillet radii in all the die edges. DOEs are planned for forging force, damage, material efficiency, mean value of strain and standard deviation value of strain. The material efficiency parameter evaluates if the die filling is appropriate or not. In relation to the mean and to the standard deviation values for strain, these are calculated from the central section of the part in the different simulations. The results obtained are shown in Table 1.

Table 1. Design of experiments for the preform, where the experiment (exp.) in bold (Case 6) is the optimum configuration.

\begin{tabular}{ccccccccc}
\hline & \multicolumn{3}{c}{ Factors } \\
\cline { 2 - 9 } Exp. & $\begin{array}{c}\text { Angle } \\
(\mathbf{})\end{array}$ & $\begin{array}{c}\text { Flash Thickness } \\
(\mathbf{m m})\end{array}$ & $\begin{array}{c}\text { Radii } \\
(\mathbf{m m})\end{array}$ & $\begin{array}{c}\text { Force } \\
(\mathbf{k N})\end{array}$ & Damage & $\begin{array}{c}\text { Strain } \\
(\text { Mean) }\end{array}$ & $\begin{array}{c}\text { Strain } \\
(\mathbf{s d})\end{array}$ & $\begin{array}{c}\text { Material } \\
\text { Efficiency }\end{array}$ \\
\hline 1 & 10 & 2 & 2 & 230 & 0.13 & 0.17 & 0.13 & 1.40 \\
2 & 30 & 2 & 2 & 202 & 0.04 & 0.10 & 0.07 & 1.00 \\
3 & 10 & 4 & 2 & 214 & 0.12 & 0.15 & 0.11 & 1.20 \\
4 & 30 & 4 & 2 & 177 & 0.04 & 0.09 & 0.06 & 1.00 \\
5 & 10 & 2 & 4 & 214 & 0.08 & 0.14 & 0.12 & 1.10 \\
$\mathbf{6}$ & $\mathbf{3 0}$ & $\mathbf{2}$ & $\mathbf{4}$ & $\mathbf{1 6 8}$ & $\mathbf{0 . 0 3}$ & $\mathbf{0 . 0 8}$ & $\mathbf{0 . 0 4}$ & $\mathbf{0 . 9 0}$ \\
7 & 10 & 4 & 4 & 163 & 0.05 & 0.11 & 0.07 & 1.00 \\
8 & 30 & 4 & 4 & 163 & 0.03 & 0.08 & 0.04 & 0.90 \\
9 & 20 & 3 & 3 & 182 & 0.06 & 0.11 & 0.07 & 1.00 \\
\hline
\end{tabular}


A statistical analysis is carried out with the software Statgraphics ${ }^{\mathrm{TM}}$ (Centurion XVI, Statpoint Technologies, Inc., Warrenton, VA, USA) and it is observed from the Pareto chart and the main effects plot that there are no significant factors for the forging force. In the case of the strain homogeneity, the most significant factor is draft angle, whereas in the case of damage, the factors that have significant importance turn out to be draft angle and fillet radii, as can be observed in Figures 5-7.
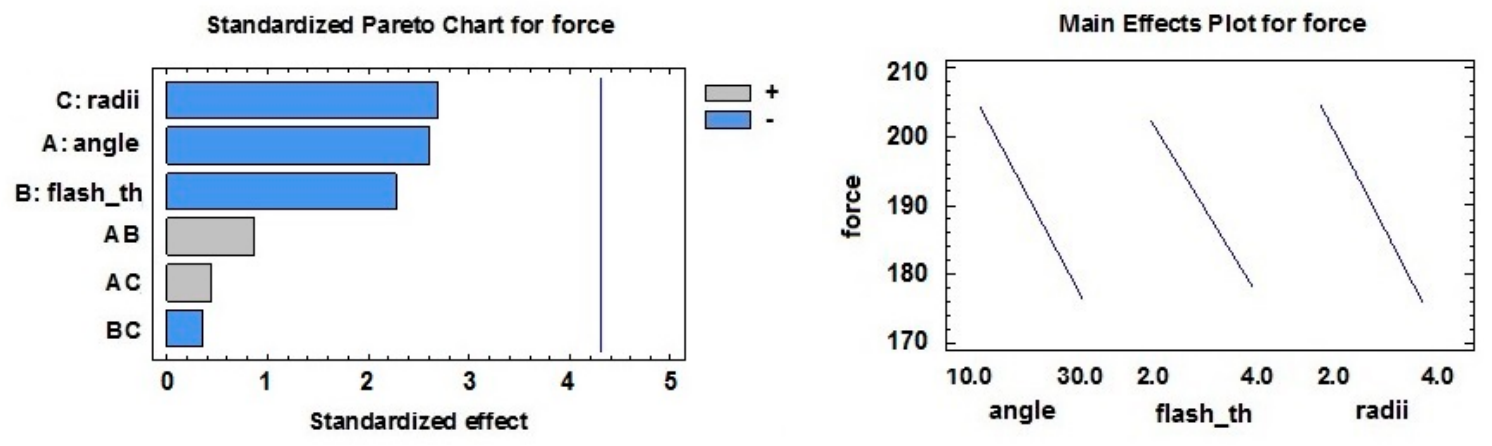

Figure 5. Design of experiments for forging force.
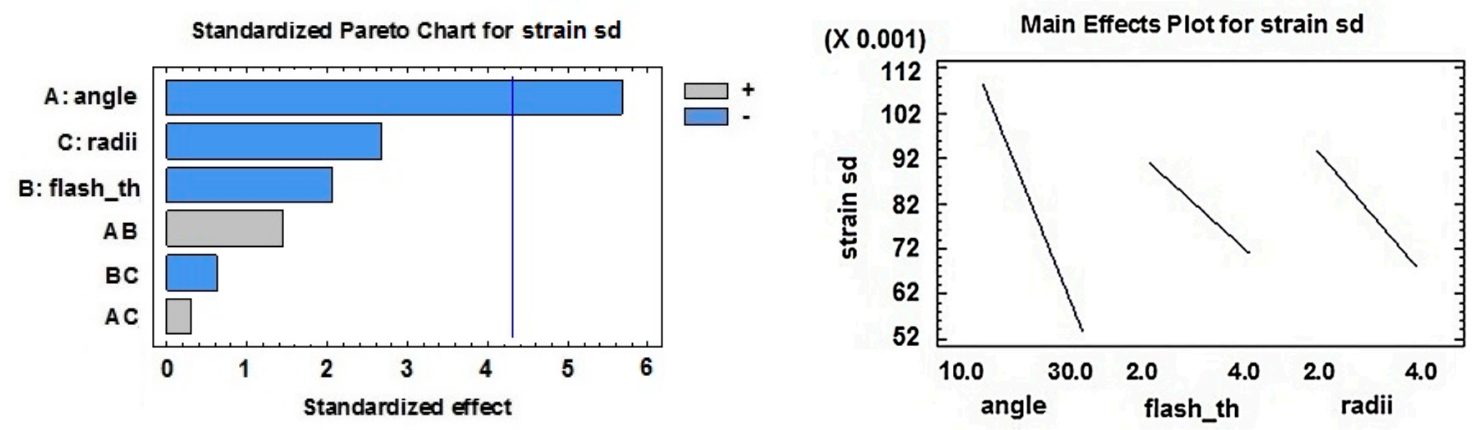

Figure 6. Design of experiments for strain homogeneity.
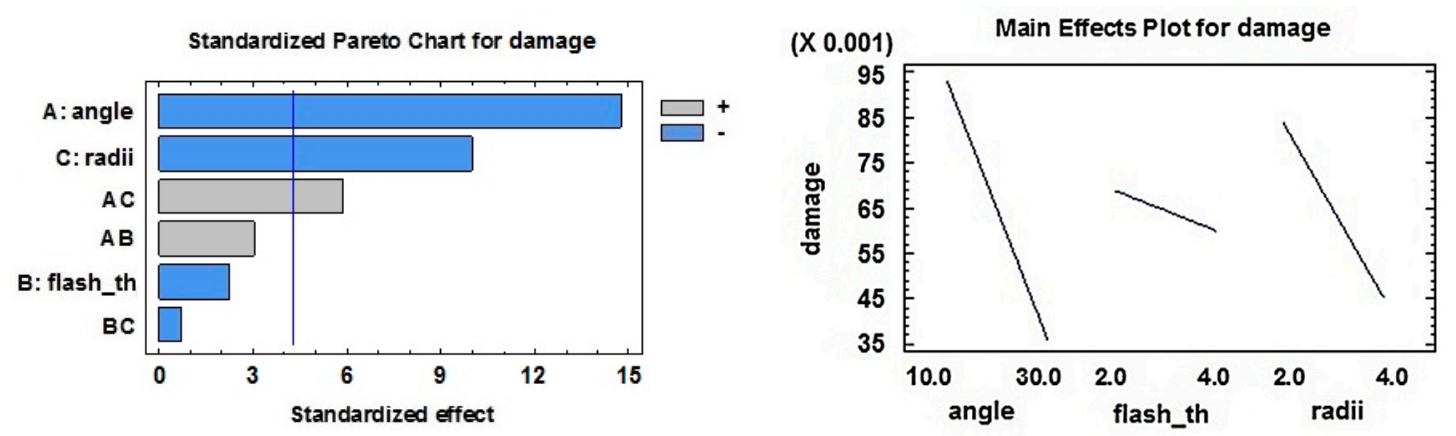

Figure 7. Design of experiments for damage.

From the data obtained, it is concluded that the optimum configuration is Case 6. The FEM results of strain, damage and die contact for the case under consideration (Case 6) are shown in Figure 8. The zone in blue colour from Figure $8 \mathrm{c}$ is not in contact with the die, which gives an idea about the filling of the die cavity. In the case of the preform, it is not interesting for flash to appear so that there is more material volume for the second forging stroke and the material is able to flow until the die cavity is completely filled. 


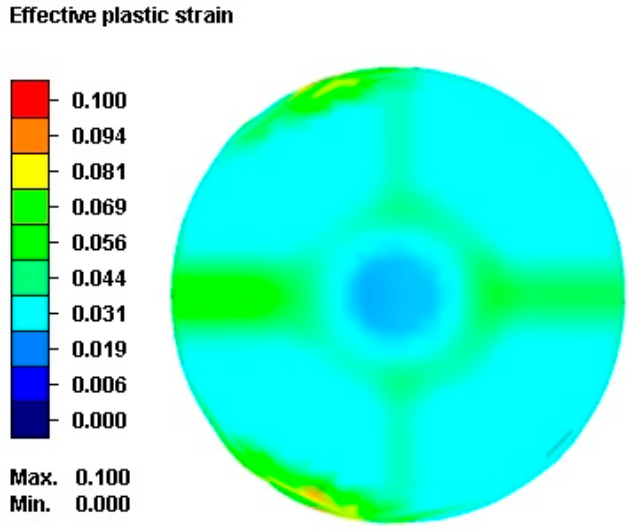

(a)
Damage

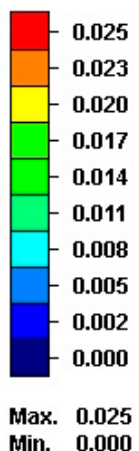

Hin 0.000

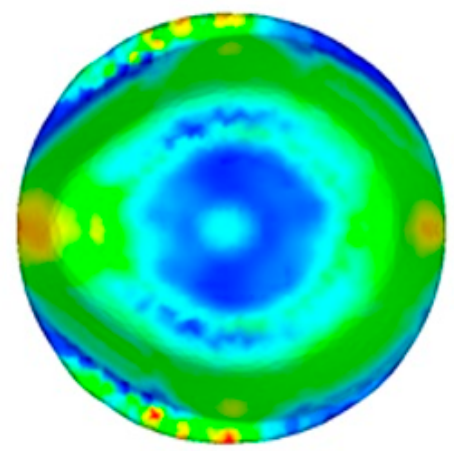

(b)

Die contact
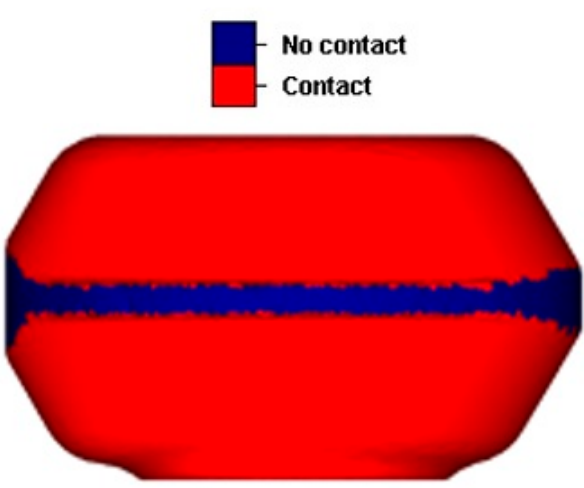

(c)

Figure 8. Strain value (a); damage value (b); and die filling (c) for the optimum case in the simulations of the cam preform.

\subsection{Cam Initial Design}

In the case of the second forging stage (see Figure 9), a procedure similar to that of the preform is followed, with the particularity that the geometry of the starting billet is obtained from the last increment in the calculation of the optimum case for the first forging stage, where this includes the accumulated plastic strain and the damage value. The rest of the simulation parameters coincide with those from the previous section.
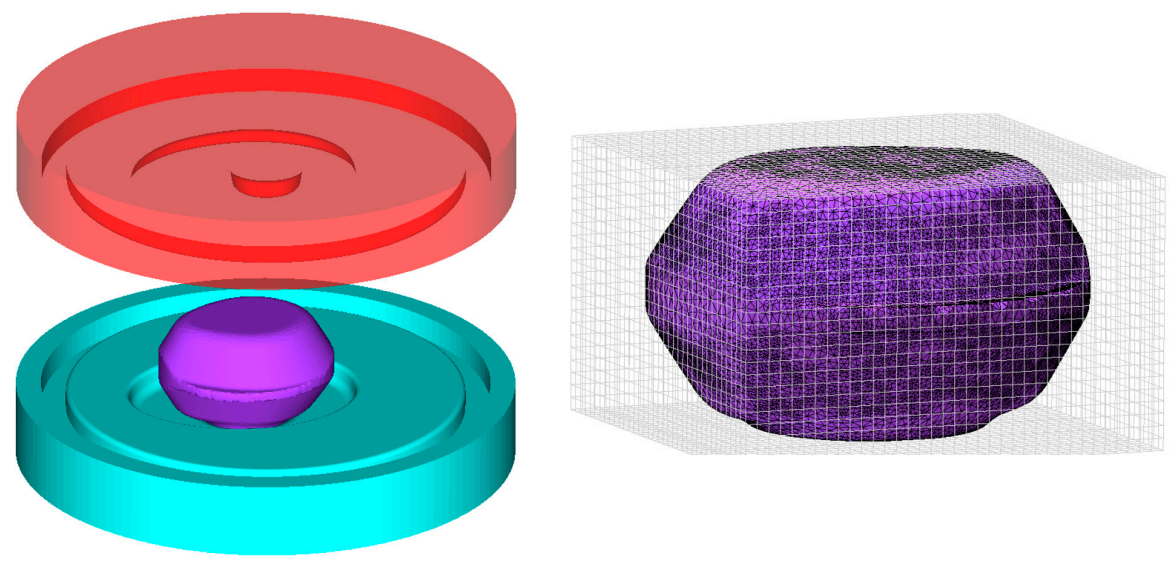

Figure 9. Simulation images from DOE Case 1. 
Table 2 shows the results for the fifteen finite volume simulations carried out for the central composite design (CCD), which consists of a $2^{3}$ factorial, six star points and one central point. The design factors and the response variables are the same as in the previous case.

Table 2. Design of experiments for the final cam, where the experiment (exp.) in bold (Case 6) is the optimum configuration.

\begin{tabular}{cccccccc}
\hline & \multicolumn{3}{c}{ Factors } & \multicolumn{4}{c}{ Results } \\
\cline { 2 - 8 } Exp. & Angle $\left.\mathbf{(}^{\circ}\right)$ & $\begin{array}{c}\text { Flash Thickness } \\
(\mathbf{m m})\end{array}$ & $\begin{array}{c}\text { Radii } \\
\mathbf{( m m})\end{array}$ & $\begin{array}{c}\text { Force } \\
\mathbf{( k N )}\end{array}$ & Damage & $\begin{array}{c}\text { Strain } \\
\mathbf{( M e a n )}\end{array}$ & $\begin{array}{c}\text { Strain } \\
(\mathbf{s d})\end{array}$ \\
\hline 1 & 10 & 2 & 2 & 787 & 0.33 & 0.64 & 0.70 \\
2 & 30 & 2 & 2 & 597 & 0.28 & 0.83 & 0.88 \\
3 & 10 & 4 & 2 & 629 & 0.33 & 0.69 & 0.71 \\
4 & 30 & 4 & 2 & 578 & 0.29 & 0.81 & 0.83 \\
5 & 10 & 2 & 4 & 586 & 0.27 & 0.72 & 0.74 \\
$\mathbf{6}$ & 30 & $\mathbf{2}$ & $\mathbf{4}$ & $\mathbf{8 7 4}$ & $\mathbf{0 . 2 6}$ & $\mathbf{0 . 8 9}$ & $\mathbf{0 . 7 8}$ \\
7 & 10 & 4 & 4 & 737 & 0.29 & 0.74 & 0.72 \\
8 & 30 & 4 & 4 & 634 & 0.28 & 0.82 & 0.88 \\
9 & 10 & 3 & 3 & 773 & 0.31 & 0.73 & 0.70 \\
10 & 30 & 3 & 3 & 620 & 0.28 & 0.85 & 0.80 \\
11 & 20 & 2 & 3 & 835 & 0.30 & 0.86 & 0.78 \\
12 & 20 & 4 & 3 & 628 & 0.30 & 0.77 & 0.73 \\
13 & 20 & 3 & 2 & 625 & 0.30 & 0.80 & 0.83 \\
14 & 20 & 3 & 4 & 782 & 0.28 & 0.78 & 0.79 \\
15 & 20 & 3 & 3 & 695 & 0.29 & 0.81 & 0.83 \\
\hline
\end{tabular}

In a similar way to the previous case, there are no significant factors in the case of forging force, whereas in the case of damage, the most significant factors turn out to be draft angle and fillet radii. When these two factors (draft angle and fillet radii) are increased, damage decreases, as may be observed in Figures 10 and 11.
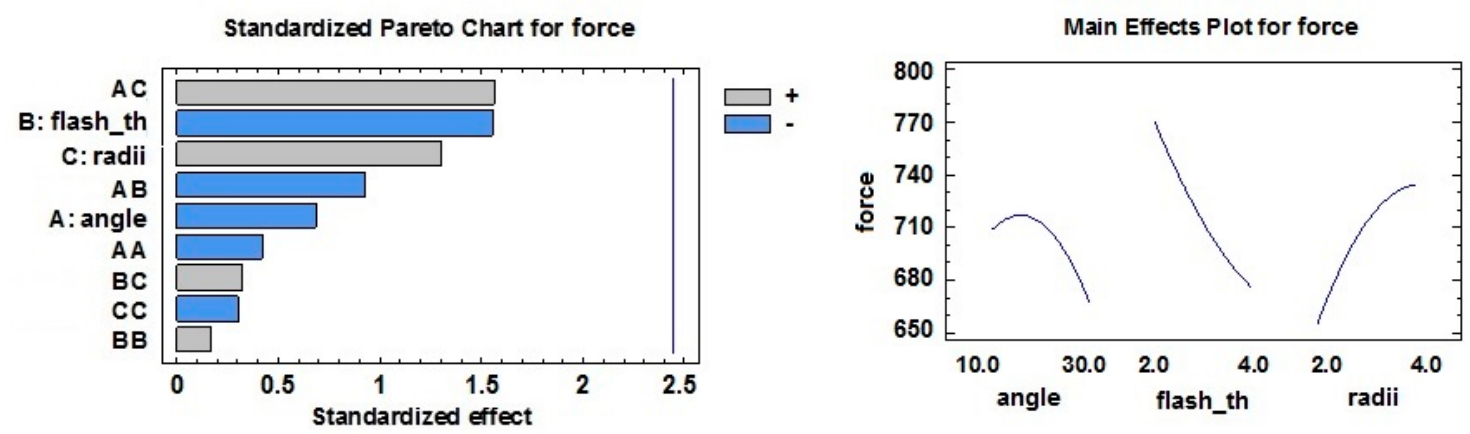

Figure 10. Pareto chart and main effects plot for forging force.
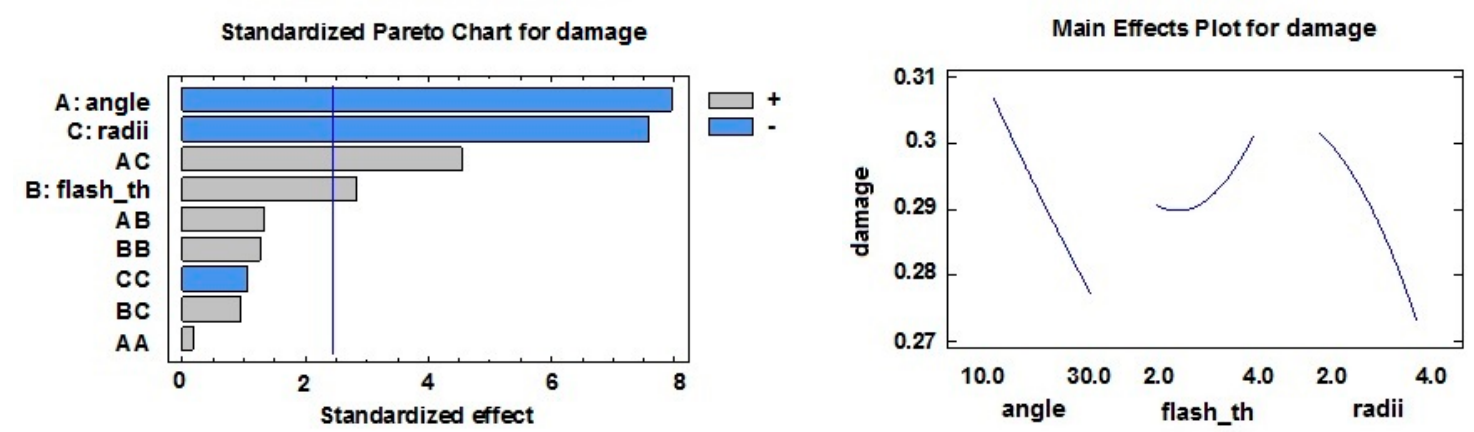

Figure 11. Pareto chart and main effects plot for damage. 
From the data obtained, it is concluded that again, the optimum configuration is Case 6, which has a draft angle of $30^{\circ}$, a flash thickness of $2 \mathrm{~mm}$ and fillet radii of $4 \mathrm{~mm}$. Several simulation images of this specific case are shown in Figure 12. Having a minimum damage value, a good die filling, a high strain mean value and a good strain homogeneity are all considered to be crucial. As in the case of the preform, the zone in blue colour from Figure 12c indicates that the material is not in contact with the die. It may be stated that the only zone that is not in contact corresponds to the flash zone, which predicts a correct filling of the die cavity.

Effective plastic strain

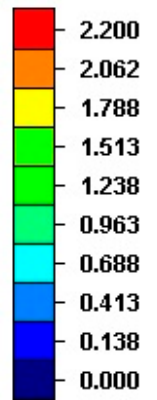

Max. 2.200 Min. 0.000

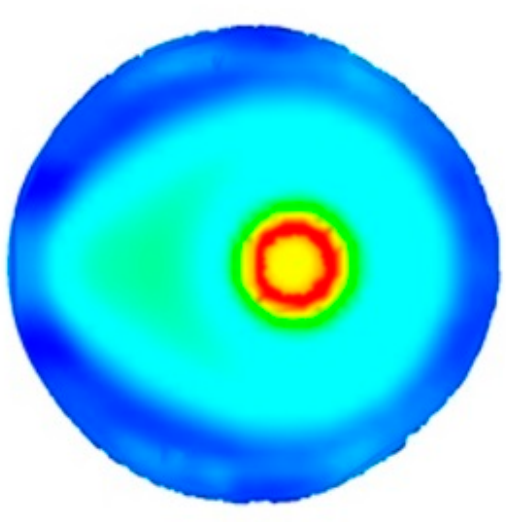

(a)

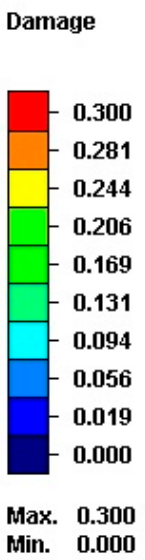

$\begin{array}{ll}\text { Max. } & 0.300 \\ \text { Min. } & 0.000\end{array}$

Die contact

- No contact

Contact

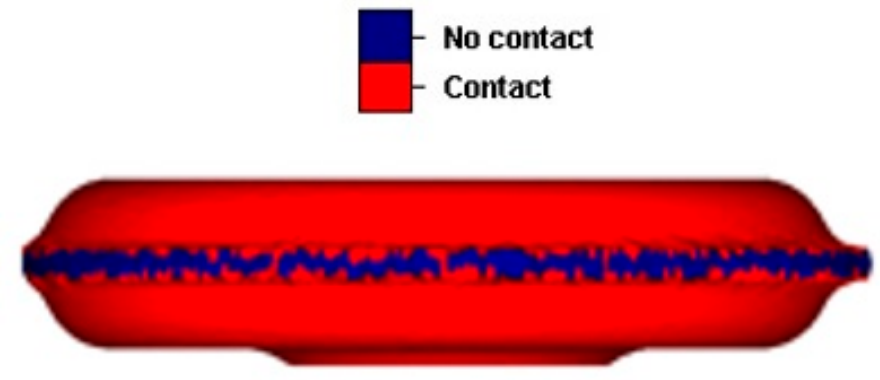

(c)

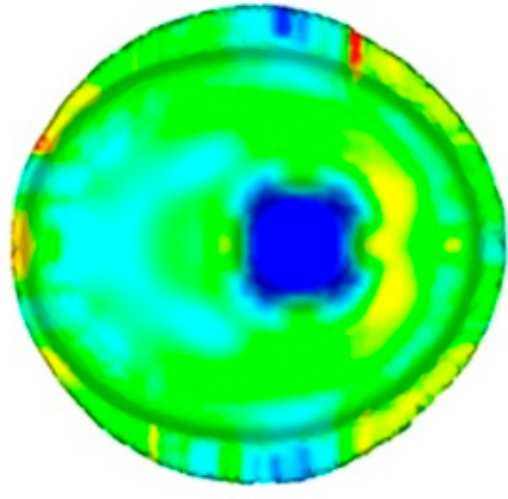

(b)

Figure 12. Strain value (a); damage value (b); and die filling (c) for the optimum case in the simulations of the cam initial design.

Prior to the manufacturing of the forging dies, diverse experimental tests were carried out in order to verify if buckling took place because of the slenderness of the preform as this phenomenon had occurred in some of the simulations. These tests showed the buckling of the preform with the initial dimensions as a result, as can be observed in Figure 13. Therefore, its length was reduced to a proportion of two to one in relation to its diameter and thus, the buckling, which might be caused by an inappropriate filling and internal cracks, was avoided. In conclusion, the preforms used in this research work were finally taken with a length of $36 \mathrm{~mm}$ and a diameter of $18 \mathrm{~mm}$. Due to the smaller amount of initial material, the cam design also had to be redefined with smaller dimensions so that the preform volume was able to fill the die cavity completely. 


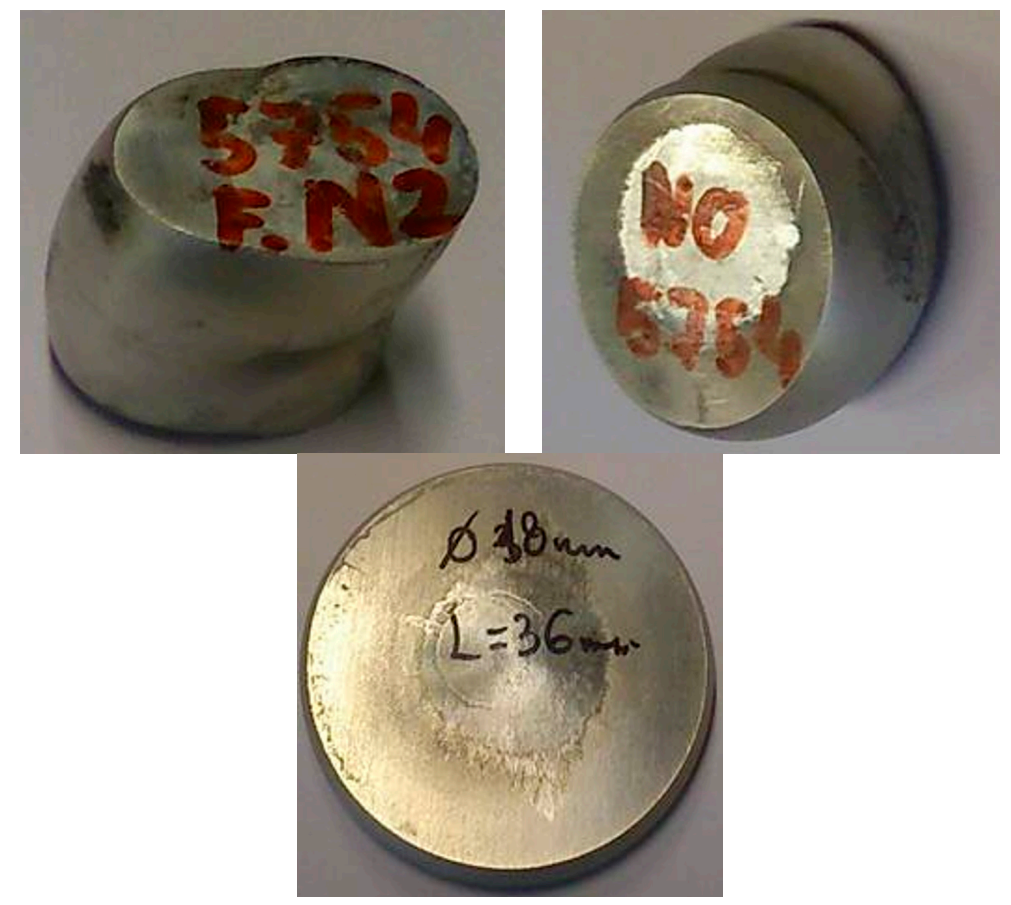

Figure 13. Billets with buckling and final test without buckling.

From the optimum design obtained by the design of experiments (which turned out to be draft angle of $30^{\circ}$, flash thickness of $2 \mathrm{~mm}$ and fillet radii of $4 \mathrm{~mm}$ ) and with the above-mentioned reduction in the size of the die cavity, a new stage of optimization in the geometry of the die cavity is carried out by FEM simulations. FEM simulations are now used instead of FV simulations as the former give a better precision than the latter, but at a higher computational cost. The element employed is a tetrahedron with five nodes, four at the vertices and one at the centre for the volume conservation. The minimum element size is $0.25 \mathrm{~mm}$, which ensures a high number of elements at the fillet radii. A coarsening factor of 2.0 is used so that the size of the inner elements is bigger and thus, the computational cost is reduced. The friction coefficient is 0.3 with a Shear's model and the type of contact employed is type node to segment. Remeshing is carried out in case of node penetration inside the die and every 20 calculation increment, where the solver used is the so-called multifrontal sparse.

After several iterations modifying both the initial position of the preform and the dimensions of the cam, a compromise solution is achieved in order to reduce the forging force, improve strain mean values and strain homogeneity and reduce the damage exerted to the cam but, at the same time, filling the die cavity completely. The cavity of the forging dies has a geometry which allows different cam profiles to be machined with a minimum radius value of $15 \mathrm{~mm}$ and a maximum one of $25 \mathrm{~mm}$.

\subsection{Cam Final Design}

Figure 14 shows the results of the final simulation for the preform, where the correct die filling, the damage value, the required forging force $(700 \mathrm{kN})$ and the plastic strain value introduced in the material may be verified.

Similarly, Figure 15 shows the results of the final simulation for the cam in terms of the die filling, the damage value, the required forging force $(2000 \mathrm{kN})$ and the plastic strain value introduced in the material. The damage value is calculated using the Crockroft-Latham criterion and it is concentrated at the flash. The required forging force is lower than the maximum capacity of the hydraulic press used in these experimental tests. In addition, the plastic strain is rather homogeneous and it has an approximate value of 1 at the zone where the profile is to be machined, which will lead to a higher surface hardness at this zone. 

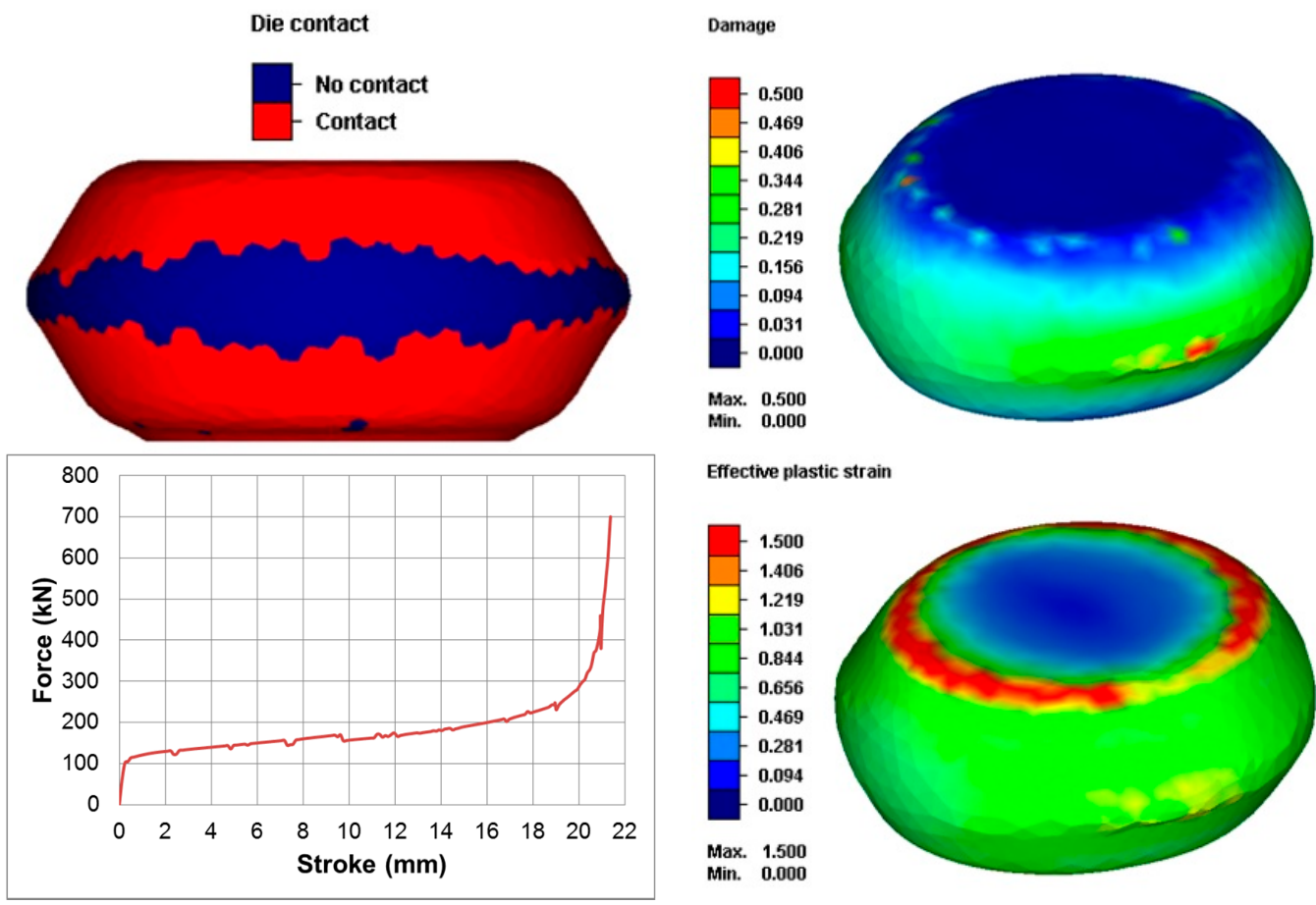

Max. 0.500

Effective plastic strain

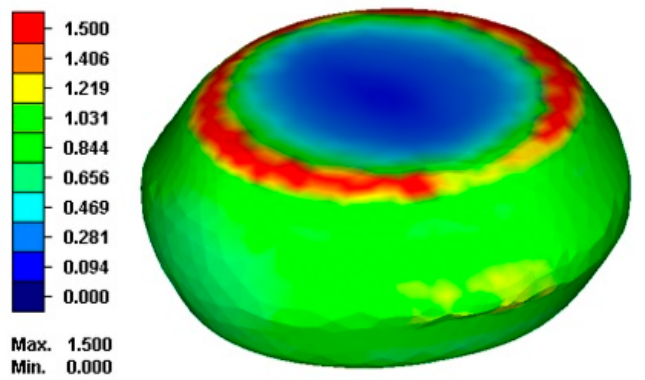

Figure 14. Cam preform.

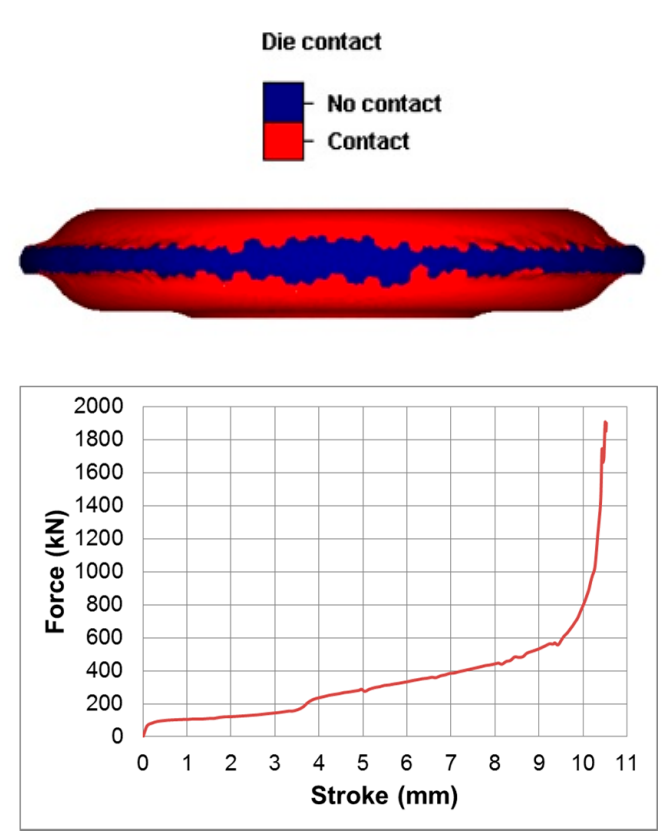

Damage

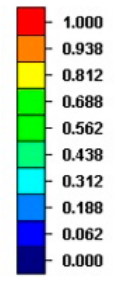

Max. $\mathbf{1 . 0 0 0}$
Min. $\mathbf{0 . 0 0 0}$

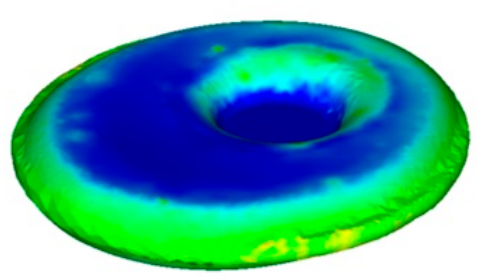

Effective plastic strain

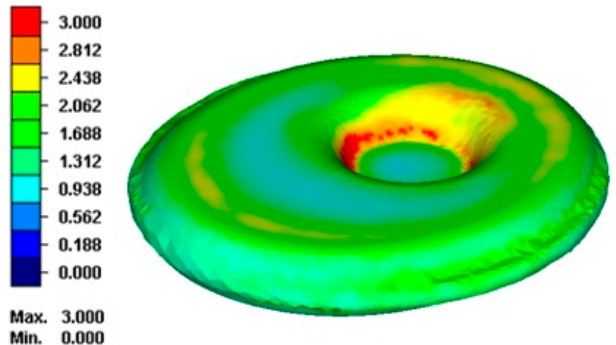

Figure 15. Second stroke for the cam.

\section{Set-Up of the Experimentation}

As was previously mentioned, the cams that are to be manufactured have a minimum radius of $15 \mathrm{~mm}$ and a maximum one of $25 \mathrm{~mm}$ and they are to be forged through two stages. Two different initial materials are used. The first of these (named as N0) consists of AA5083 as cast which is subjected to a heat treatment of annealing following the recommendations by ASM [25]. The second material (named as N2F) is obtained from N0 material which is subjected to equal channel angular pressing 
(ECAP) twice and with route C [4]. A set of ECAP dies with a channel diameter of $20 \mathrm{~mm}$ and an intersection angle between the two channels of $90^{\circ}$ is used. Moreover, the fillet radii between the channels have the same values and they are equal to $2.5 \mathrm{~mm}$. Subsequently, this N2F material is subjected to a heat treatment of recovery, which is named as flash treatment and which consists in increasing the material temperature at a velocity of $12{ }^{\circ} \mathrm{C} / \mathrm{min}$ inside a furnace until a temperature of $340{ }^{\circ} \mathrm{C}$ is reached and then the material is cooled in water.

The manufacturing of cams with both starting materials is carried out by a forging process at a temperature of $200{ }^{\circ} \mathrm{C}$ and from a preform of $18 \mathrm{~mm}$ in diameter and $36 \mathrm{~mm}$ in length. In order to manufacture them, a hydraulic press with a heating system for the set of die-holders is used, where the forging dies designed in this present research work are inserted in the previously-mentioned die-holders [13]. A Five-minute wait is required with the cam preform placed on the forging die before carrying out the first forging stage so that the temperature of the preform reaches $200^{\circ} \mathrm{C}$. In the case of the second forging stage, this is carried out just after the first one. In both cases, the descent velocity of the upper plate of the press is $1 \mathrm{~mm} / \mathrm{s}$ and aqueous-based polytetrafluoroethylene (Teflon ${ }^{\circledR}$ ) is used as a lubricant.

The set of forging dies designed from the optimization process described in this present study and used to manufacture the above-mentioned cams can be seen in Figure 16. They were made of F522 steel as this may be quenched with no practical change in its geometry and with final hardness values of around $60 \mathrm{HRC}$.

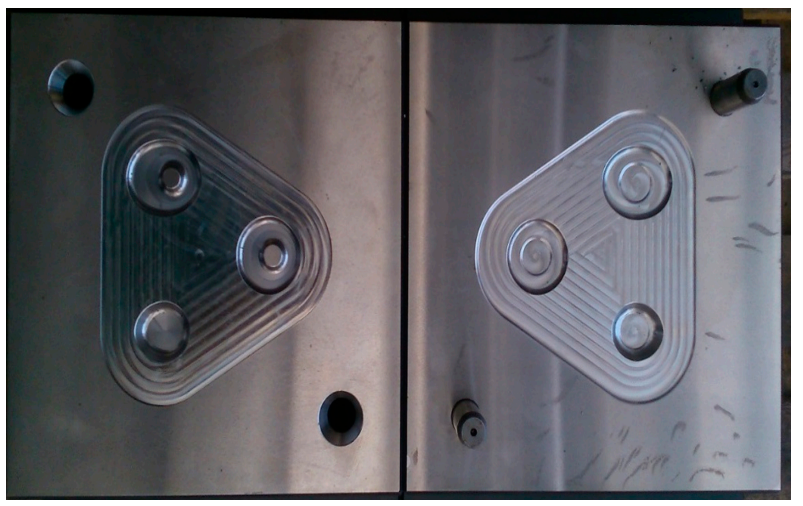

Figure 16. Manufactured forging dies.

The cams finally manufactured may be observed in Figure 17. In the figure on the left, the different steps (initial billet of the starting material, ECAP-processed billet and machined preform) in order to obtain the preform are shown, whereas in the figure on the right, several final parts obtained after the second forging stroke are shown.

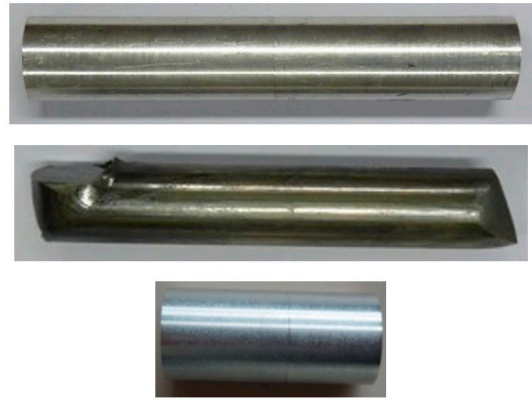

(a)

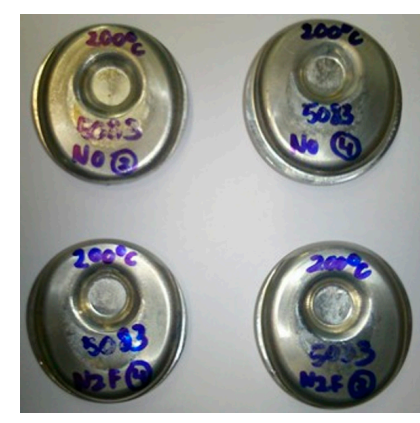

(b)

Figure 17. (a,b) Preform obtained from starting material and cams manufactured after the second forging stroke. 
The preparation of samples in order to obtain optical microscopy micrographs requires a metallographic saw, which does not modify their microstructure, and their subsequent mounting in a transparent resin. After encapsulating the samples, they are prepared with several abrasive papers and polishing cloths and then, they are subjected to Barker's reagent.

Once this previous process is carried out, optical microscopy micrographs at $100 \times$ and $20 \times$ are taken with the use of polarized filters. In addition, Scanning Electron Microscopy (SEM) is also utilised. For this case, the samples are electropolished with perchloric acid, ethanol and glycerine. All the SEM micrographs are taken at $1000 \times, 2500 \times, 10,000 \times$ and $25,000 \times$ with backscattered electrons.

\section{Discussion of Results}

In this section, the mechanical properties of the manufactured cams are discussed. In order to do this, microhardness measurements are taken from the cams and their microstructure is observed through optical microscopy and SEM, as was previously mentioned.

Regarding microhardness measurements, three different zones are selected at the outer part of the cam, as this zone undergoes the highest value of wear and thus, a higher value of hardness is required. As can be observed in Figure 18, zone A corresponds with the bottom zone of maximum radius, zone $B$ with the upper zone of minimum radius and zone $C$ with the lateral zone of minimum radius. Five microhardness measurements are taken in each zone in order to have more accurate data along with the calculation of the mean and the standard deviation values.

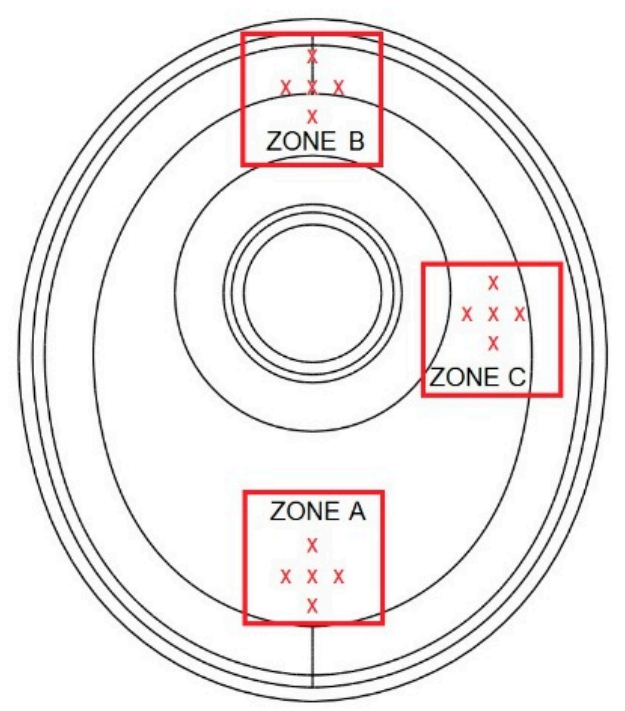

Figure 18. Zones selected for the measurements of microhardness.

A microhardness tester Mitutoyo HM-200 ${ }^{\circledR}$ (Mitutoyo Corporation, Kawasaki, Japan) is used in order to carry out these measurements. Vickers microhardness tests are performed with a load value of $3 \mathrm{~N}$. In this load range, the uncertainty value for the equipment is $\pm 1 \%$ if room temperature is between 22 and $24{ }^{\circ} \mathrm{C}$. The approach time taken is $3 \mathrm{~s}$, the load maintenance time is $10 \mathrm{~s}$ and the withdrawal time is $3 \mathrm{~s}$. With this procedure, the results obtained in the measurements are shown in Tables 3 and 4 .

In both cases (N0 material and N2F material), the highest microhardness value occurs at zone C. It is observed that a better homogeneity is achieved in the case of the samples with N2F material. In addition, an increase of $10.3 \%$ in the mean value of microhardness is achieved for N2F material in relation to N0 material, as is shown in Figure 19. 
Table 3. Microhardness measurements of the cam with N0 material.

\begin{tabular}{|c|c|c|c|c|}
\hline AA5083 No & Position $(x, y)(\mathrm{mm})$ & Hardness Vickers (Hv) & Mean (Hv) & St Deviation (Hv) \\
\hline A & $\begin{array}{c}(0,0) \\
(2.5,0) \\
(-2.5,0) \\
(0,2.5) \\
(0,-2.5)\end{array}$ & $\begin{array}{l}101.8 \\
109.4 \\
106.2 \\
108.7 \\
110.3\end{array}$ & 107.3 & 3.4 \\
\hline B & $\begin{array}{c}(0,0) \\
(2.5,0) \\
(-2.5,0) \\
(0,2.5) \\
(0,-2.5)\end{array}$ & \begin{tabular}{l|}
103.0 \\
107.8 \\
103.2 \\
108.8 \\
105.9
\end{tabular} & 105.7 & 2.6 \\
\hline C & $\begin{array}{c}(0,0) \\
(2.5,0) \\
(-2.5,0) \\
(0,2.5) \\
(0,-2.5)\end{array}$ & $\begin{array}{l}109.0 \\
113.1 \\
105.8 \\
110.1 \\
109.7\end{array}$ & 109.5 & 2.6 \\
\hline Total & - & - & 107.5 & 3.1 \\
\hline
\end{tabular}

Table 4. Microhardness measurements of the cam with N2F material.

\begin{tabular}{|c|c|c|c|c|}
\hline AA5083 N2F & Position $(x, y)(\mathrm{mm})$ & Hardness Vickers (Hv) & Mean (Hv) & St Deviation (Hv) \\
\hline \multirow{5}{*}{ A } & $(0,0)$ & 117.4 & \multirow{5}{*}{117.3} & \multirow{5}{*}{1.8} \\
\hline & $(2.5,0)$ & 114.4 & & \\
\hline & $(-2.5,0)$ & 118.2 & & \\
\hline & $(0,2.5)$ & 119.2 & & \\
\hline & $(0,-2.5)$ & 117.5 & & \\
\hline \multirow{5}{*}{ B } & $(0,0)$ & 118.2 & \multirow{5}{*}{117.8} & \multirow{5}{*}{2.7} \\
\hline & $(2.5,0)$ & 113.4 & & \\
\hline & $(-2.5,0)$ & 120.1 & & \\
\hline & $(0,2.5)$ & 119.7 & & \\
\hline & $(0,-2.5)$ & 117.7 & & \\
\hline \multirow{5}{*}{ C } & $(0,0)$ & 121.4 & \multirow{5}{*}{120.7} & \multirow{5}{*}{1.2} \\
\hline & $(2.5,0)$ & 121.8 & & \\
\hline & $(-2.5,0)$ & 120.4 & & \\
\hline & $(0,2.5)$ & 118.7 & & \\
\hline & $(0,-2.5)$ & 121.2 & & \\
\hline Total & - & - & 118.6 & 2.4 \\
\hline
\end{tabular}

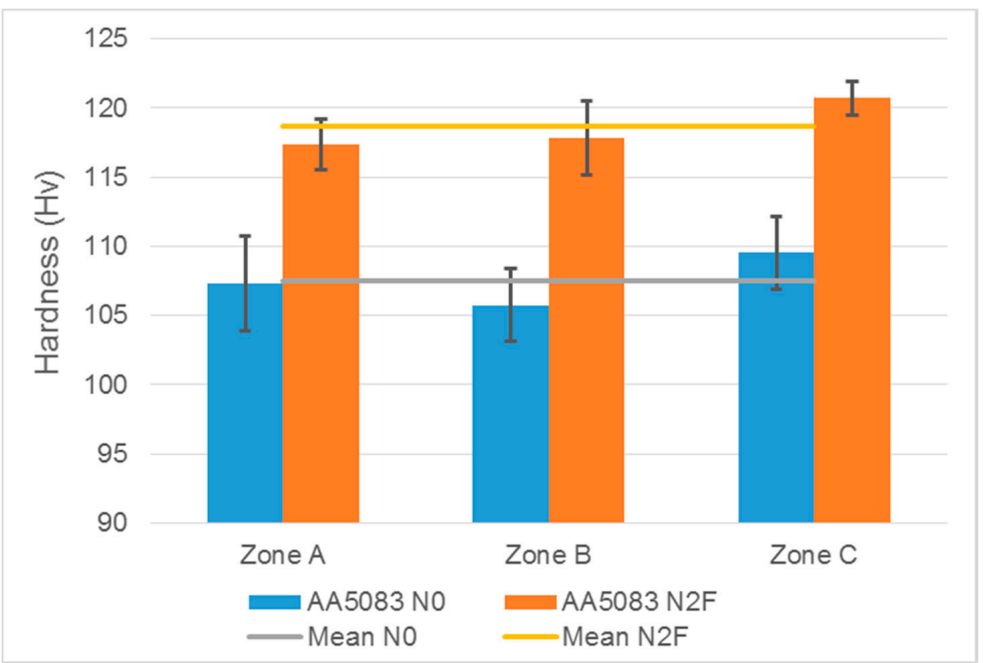

Figure 19. Comparison of microhardness values (Hv) for N0 and N2F initial materials.

Figure 20 shows optical micrographs taken from the cams with the two initial materials: N0 and N2F. In both cases, stretched grains are observed because of the forging process. In the micrographs from N2F material, it is observed that there are a higher number of deformation bands. 


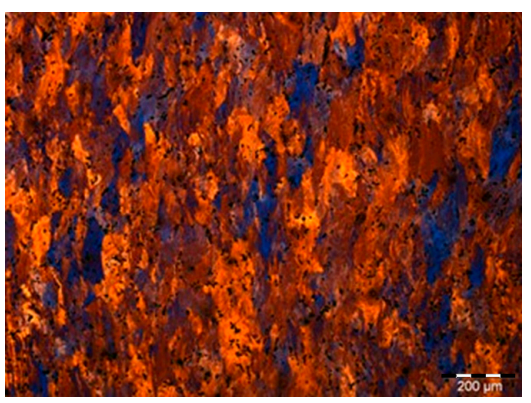

(a)

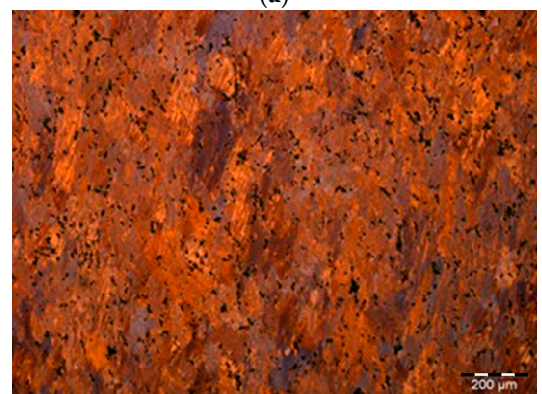

(c)

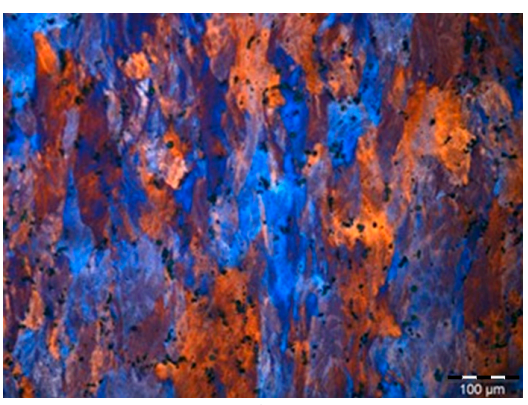

(b)

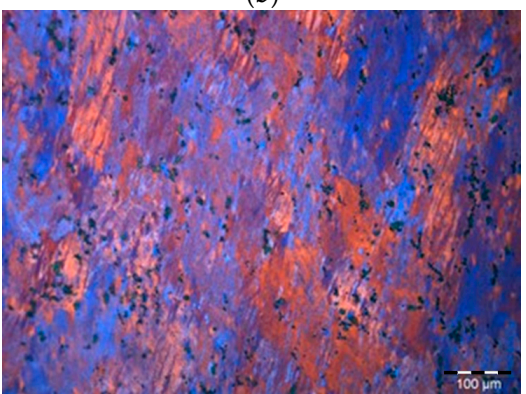

(d)

Figure 20. Optical micrographs of the cams with N0 and N2F materials: (a) N0 at 100×; (b) N0 at 200 × ; (c) $\mathrm{N} 2 \mathrm{~F}$ at $100 \times$; and (d) $\mathrm{N} 2 \mathrm{~F}$ at $200 \times$.

Figure 21 shows SEM micrographs for the cams with N0 initial material whereas Figure 22 shows those corresponding with the cams with $\mathrm{N} 2 \mathrm{~F}$ initial material. In both cases, the grain size turns out to be lower than $1 \mu \mathrm{m}$ and even grains with a size of around $250 \mathrm{~nm}$ may be found.

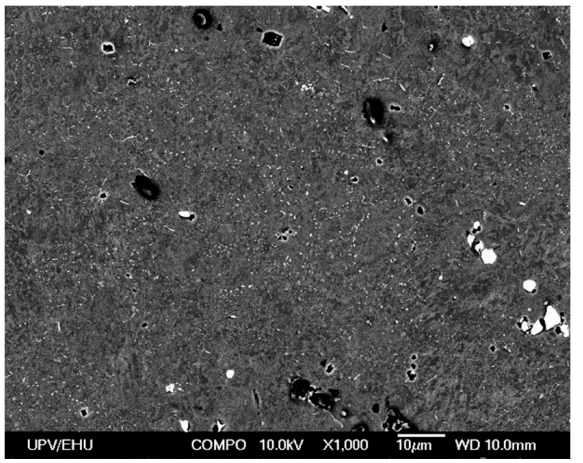

(a)

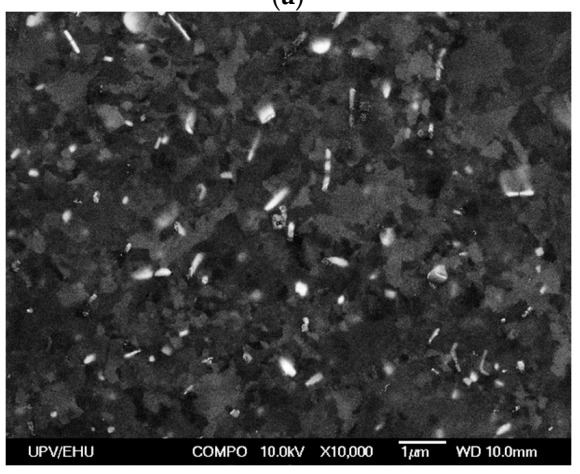

(c)

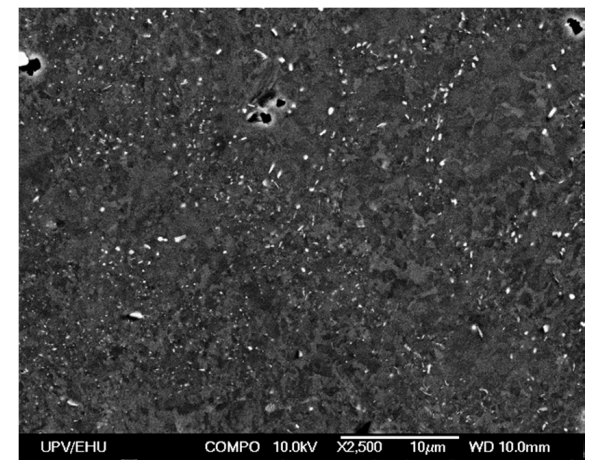

(b)

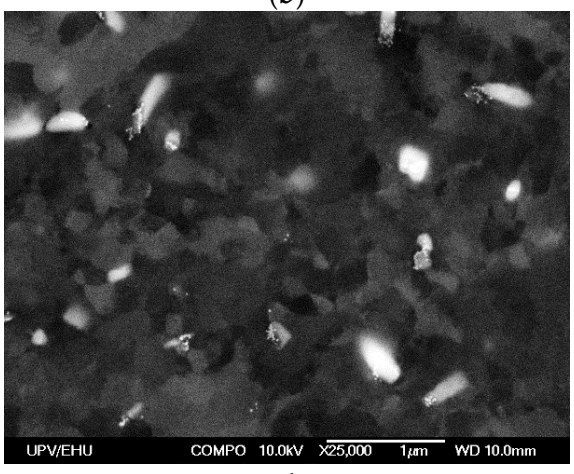

(d)

Figure 21. SEM micrographs of the cams with N0 material: (a) N0 at 1000×; (b) N0 at 2500×; (c) N0 at $10,000 \times$; and (d) N0 at $25,000 \times$. 


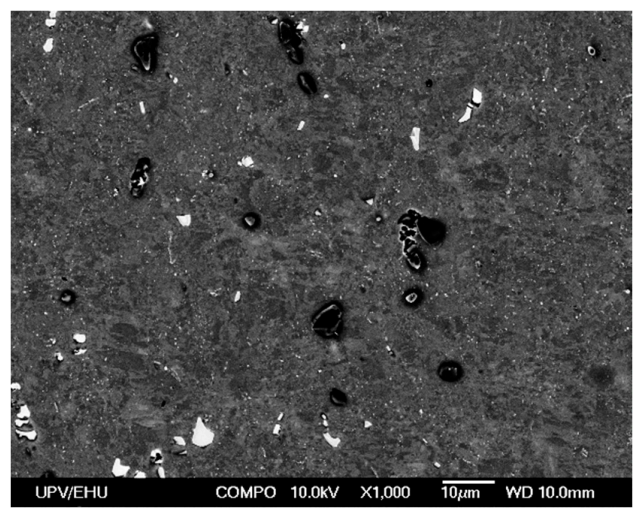

(a)

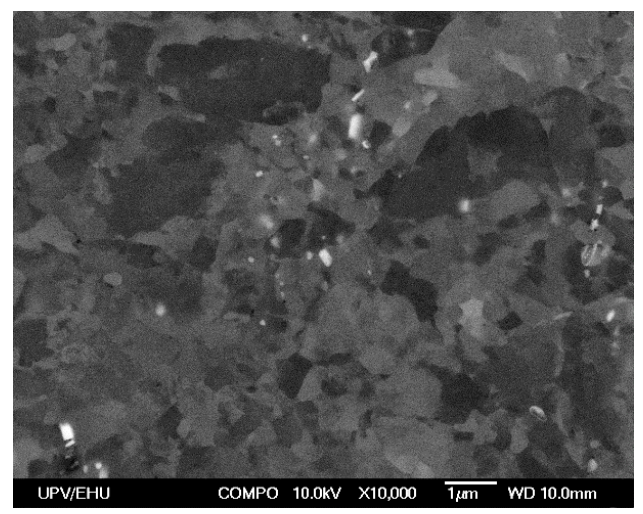

(c)

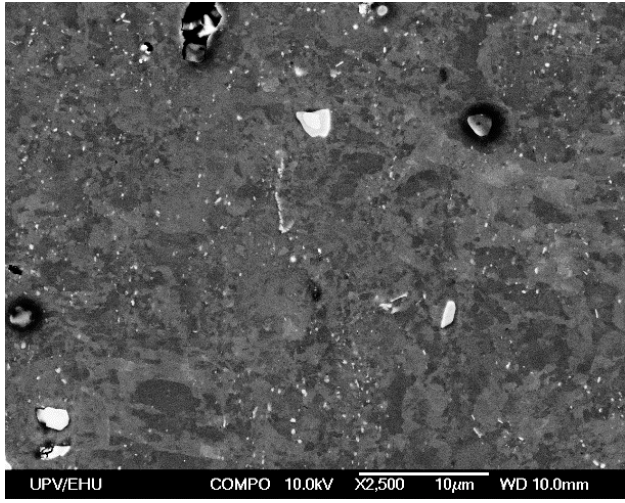

(b)

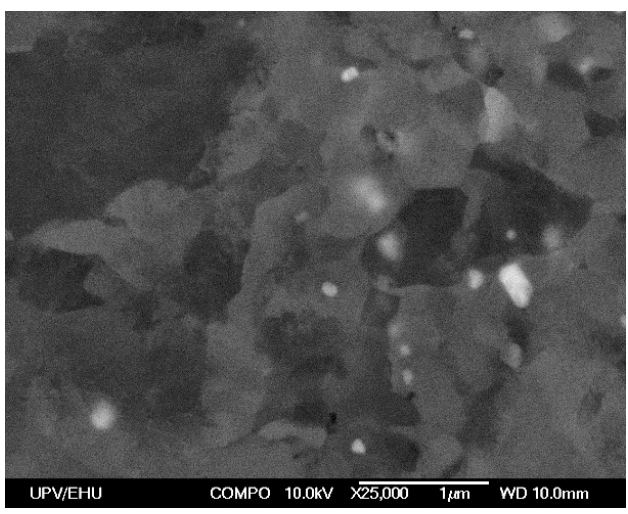

(d)

Figure 22. SEM micrographs of the cams with N2F material: (a) N2F at 1000×; (b) N2F at 2500×; (c) $\mathrm{N} 2 \mathrm{~F}$ at $10,000 \times$; and (d) $\mathrm{N} 2 \mathrm{~F}$ at $25,000 \times$.

Furthermore, a comparative study is made between the experimental results and the FEM simulations. For the FEM simulations, flow rules of N0 and N2F initial materials are used, where these are obtained from isothermal compression tests and by the application of a new constitutive model developed by these present authors [26].

With regard to the forging force, Figure 23 shows a comparison between the experimental forging force and that calculated from the simulations. As can be observed in Figure 23, the experimental force turns out to be a little higher than the simulated one but the approach of the latter is good. The maximum value for the forging force is lower than $3000 \mathrm{kN}$, which is the maximum capacity of the hydraulic press, and the final maximum force values for both the first and the second forging stage are smaller in the case of N2F material, which leads to a lower wear value for the forging dies. Taking this into account along with the fact that no cracks appear in any of the tests, it may be affirmed that N2F material has a better forgeability.

Figure 24 shows the plastic strain value, the damage value and the die contact obtained in the FEM simulations for N0 initial material. The plastic strain values obtained in the simulations may be compared to the microhardness values from Tables 3 and 4 . For example, it may be observed in Figure 24 that, in the case of the second forging stage, the strain value is higher at zone $C$, which is the lateral zone (in red) close to the guide from the upper die, and this agrees quite well with the experimental microhardness measurements. 


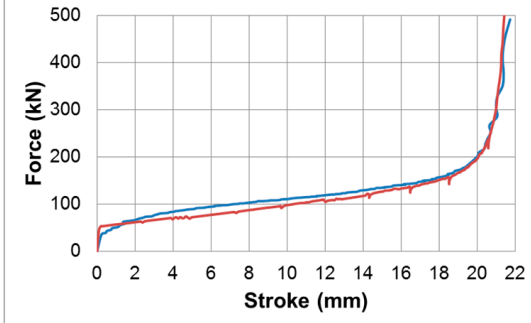

—Exp-N0-5083-Preform —FEM-N0-5083-Preform

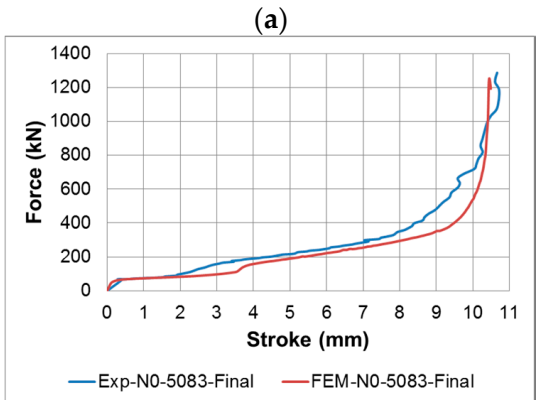

(c)

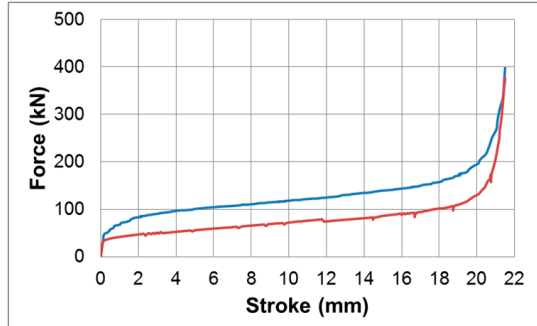

—Exp-N2F-5083-Preform -FEM-N2F-5083-Preform

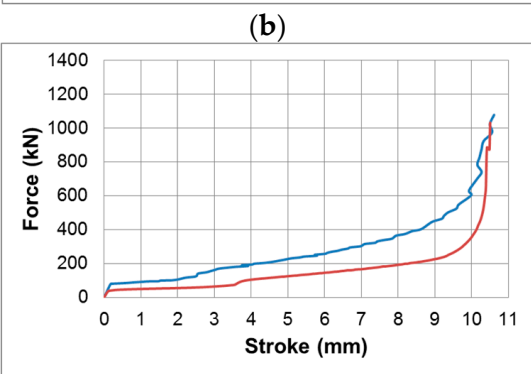

—Exp-N2F-5083-Final _-FEM-N2F-5083-Final

(d)

Figure 23. Forging force values obtained in the experiments: (a) first stage for N0; (b) first stage for N2F; (c) second stage for N0; and (d) second stage for N2F.
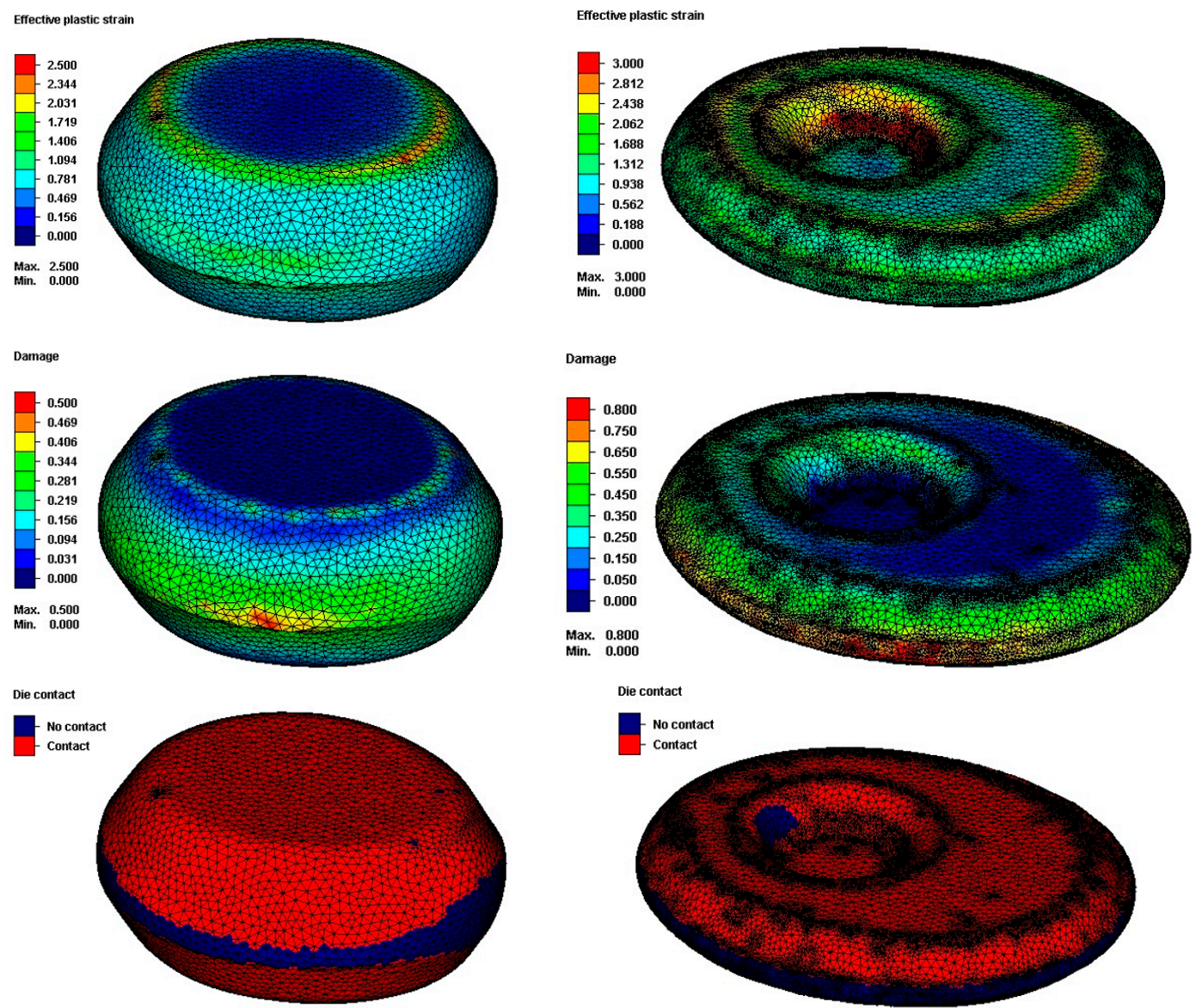

Figure 24. Plastic strain, damage and die contact values obtained in the FEM simulations for N0 starting material. 
In relation to the damage value, as no cracks appear, it is assumed that the material can undergo a value of 0.8 (according to the Crockroft-Latham criterion) because this is the maximum value achieved in the simulations at the zone of the flash.

It may also be pointed out that there is a good approach between the geometry of the manufactured cams and the results obtained in the FEM simulations. In addition, Figure 24 shows the small amount of material waste in the form of flash, which leads to the conclusion that this design makes good use of the ECAP-processed material.

\section{Conclusions}

This research work demonstrates that it is feasible to manufacture cams from AA5083 using the ECAP processing and a subsequent isothermal forging. An increase of $10.3 \%$ in the microhardness mean value has been verified for the material previously processed by ECAP compared to that obtained from material with no previous deformation.

From the data obtained, it may be concluded that the optimum configuration for the geometry shown in this work is that given by Case 6, which has a draft angle of $30^{\circ}$, a flash thickness of $2 \mathrm{~mm}$ and fillet radii of $4 \mathrm{~mm}$. This geometry has a minimum damage value compared to the different geometries shown in this study, a good die filling, a high strain mean value and a good strain homogeneity.

In both cases (N0 material and N2F material), the highest microhardness value occurs at zone $\mathrm{C}$. It can be observed that a better homogeneity is achieved in the case of the samples with N2F material. A higher number of deformation bands and subgrains have been observed in the cams with N2F material, which may lead to dynamic recrystallization processes during the forging process and thus, to an improvement in forgeability.

The maximum value for the forging force is lower than $3000 \mathrm{kN}$, which is the maximum capacity of the hydraulic press employed in the experiments, and the final maximum force values for both the first and the second forging stage are smaller in the case of N2F material, which leads to a lower wear value for the forging dies. Taking this into account, along with the fact that no cracks appear in any of the tests, it may be affirmed that N2F material has a better forgeability.

Acknowledgments: The authors of this present research work acknowledge the support given by the Spanish Ministry of Economy and Competitiveness through the Research Project DPI2013-41954-P.

Author Contributions: Daniel Salcedo, Carmelo J. Luis, Rodrigo Luri, Ignacio Puertas, Javier León and Juan P. Fuertes have approximately equally contributed to most of the research tasks.

Conflicts of Interest: The authors declare no conflict of interest.

\section{References}

1. Priest, M.; Taylor, C.M. Automobile engine tribology-Approaching the surface. Wear 2000, 241, $193-203$. [CrossRef]

2. Lee, S.W.; Lee, D.G. Composite hybrid valve lifter for automotive engines. Compos. Struct. 2005, 71, $26-33$. [CrossRef]

3. Segal, V.M. Materials processing by simple shear. Mater. Sci. Eng. A 1995, 197, 157-164. [CrossRef]

4. Valiev, R.Z.; Langdon, T.G. Principles of equal-channel angular pressing as a processing tool for grain refinement. Prog. Mater. Sci. 2006, 51, 881-981. [CrossRef]

5. El-Danaf, E.A. Mechanical properties, microstructure and texture of single pass equal channel angular pressed 1050, 5083, 6082 and 7010 aluminum alloys with different dies. Mater. Des. 2011, 32, 3838-3853. [CrossRef]

6. El-Danaf, E.A. Mechanical properties, microstructure and micro-texture evolution for 1050AA deformed by equal channel angular pressing (ECAP) and post ECAP plane strain compression using two loading schemes. Mater. Des. 2012, 34, 793-807. [CrossRef]

7. Baig, M.; El-Danaf, E.; Mohammad, J.A. Thermo-mechanical responses of an aluminum alloy processed by equal channel angular pressing. Mater. Des. 2014, 57, 510-519. [CrossRef] 
8. Zha, M.; Li, Y.-J.; Mathiesen, R.; Bjørge, R.; Roven, H.J. Microstructure, hardness evolution and thermal stability of binary Al-7Mg alloy processed by ECAP with intermediate annealing. Trans. Nonferr. Met. Soc. China 2014, 24, 2301-2306. [CrossRef]

9. Luri, R.; Fuertes, J.P.; Luis, C.J.; Salcedo, D.; Puertas, I.; León, J. Experimental modelling of critical damage obtained in Al-Mg and Al-Mn alloys for both annealed state and previously deformed by ECAP. Mater. Des. 2016, 90, 881-890. [CrossRef]

10. Fakhar, N.; Fereshteh-Saniee, F.; Mahmudi, R. High strain-rate superplasticity of fine- and ultrafine-grained AA5083 aluminum alloy at intermediate temperatures. Mater. Des. 2015, 85, 342-348. [CrossRef]

11. Fakhar, N.; Fereshteh-Saniee, F.; Mahmudi, R. Significant improvements in mechanical properties of AA5083 aluminum alloy using dual equal channel lateral extrusion. Trans. Nonferr. Met. Soc. China 2016, 26, 3081-3090. [CrossRef]

12. Kim, W.J.; Sa, Y.K.; Kim, H.K.; Yoon, U.S. Plastic forming of the equal-channel angular pressing processed 6061 aluminum alloy. Mater. Sci. Eng. A 2008, 487, 360-368. [CrossRef]

13. Luis Pérez, C.J.; Salcedo Pérez, D.; Puertas Arbizu, I. Design and mechanical property analysis of ultrafine grained gears from AA5083 previously processed by equal channel angular pressing and isothermal forging. Mater. Des. 2014, 63, 126-135. [CrossRef]

14. Choi, J.S.; Nawaz, S.; Hwang, S.K.; Lee, H.C.; Im, Y.T. Forgeability of ultra-fine grained aluminum alloy for bolt forming. Int. J. Mech. Sci. 2010, 52, 1269-1276. [CrossRef]

15. Yanagida, A.; Joko, K.; Azushima, A. Formability of steels subjected to cold ECAE process. J. Mater. Process. Technol. 2008, 201, 390-394. [CrossRef]

16. Jin, Y.G.; Baek, H.M.; Im, Y.-T.; Jeon, B.C. Continuous ECAP process design for manufacturing a microstructurerefined bolt. Mater. Sci. Eng. A 2011, 530, 462-468. [CrossRef]

17. Jin, Y.G.; Baek, H.M.; Hwang, S.K.; Im, Y.T.; Jeon, B.C. Continuous high strength aluminum bolt manufacturing by the spring-loaded ECAP system. J. Mater. Process. Technol. 2012, 212, 848-855. [CrossRef]

18. Kim, J.H.; Hwang, S.K.; Im, Y.-T.; Son, I.-H.; Bae, C.M. High-strength bolt-forming of fine-grained aluminum alloy 6061 with a continuous hybrid process. Mater. Sci. Eng. A 2012, 552, 316-322. [CrossRef]

19. Puertas, I.; Luis Pérez, C.J.; Salcedo, D.; León, J.; Fuertes, J.P.; Luri, R. Design and mechanical property analysis of AA1050 turbine blades manufactured by equal channel angular extrusion and isothermal forging. Mater. Des. 2013, 52, 774-784. [CrossRef]

20. Lee, J.H.; Kang, S.H.; Yang, D.Y. Novel forging technology of a magnesium alloy impeller with twisted blades of micro-thickness. CIRP Ann. Manuf. Technol. 2008, 57, 261-264. [CrossRef]

21. Luis, C.J.; Salcedo, D.; León, J.; Puertas, I.; Fuertes, J.P.; Luri, R. Manufacturing of nanostructured rings from previously ECAE-processed AA5083 alloy by isothermal forging. J. Nanomater. 2013, 2013, 613102. [CrossRef]

22. Cisar, L.; Yoshida, Y.; Kamado, S.; Kojima, Y.; Watanabe, F. Microstructures and tensile properties of ECAE-processed and forged AZ31 magnesium alloy. Mater. Trans. 2003, 44, 476-483. [CrossRef]

23. Fuertes, J.P.; Luis, C.J.; Luri, R.; Salcedo, D.; León, J.; Puertas, I. Design, simulation and manufacturing of a connecting rod from ultra-fine grained material and isothermal forging. J. Manuf. Processes 2016, 21, 56-68. [CrossRef]

24. Salcedo, D.; Luis, C.J.; Puertas, I.; León, J.; Luri, R.; Fuertes, J.P. FEM Modelling and Experimental Analysis of an AA5083 Turbine Blade from ECAP Processed Material. Mater. Manuf. Processes 2014, 29, 434-441. [CrossRef]

25. ASM Handbook Committee. ASM HandBook, Heat Treating; ASM International: Materials Park, OH, USA, 1991; Volume 4.

26. León, J.; Luis, C.J.; Fuertes, J.P.; Puertas, I.; Luri, R.; Salcedo, D. A proposal of a constitutive description for aluminium alloys in both cold and hot working. Metals 2016, 6, 244. [CrossRef]

(C) 2017 by the authors. Licensee MDPI, Basel, Switzerland. This article is an open access article distributed under the terms and conditions of the Creative Commons Attribution (CC BY) license (http:/ / creativecommons.org/licenses/by/4.0/). 